\title{
Body ecology: a new philosophy through cosmotic emersiology
}

Bernard Andrieu ${ }^{1, *}$, Petrucia da Nobrega ${ }^{2}$, Olivier Sirost ${ }^{3}$

1 University Paris-Descartes, France

2 Universidade Federal do Rio Grande do Norte, Natal, Brasil

3 University Rouen, France

* Corresponding author: Bernard Andrieu (bandrieu59@orange.fr)

\section{ABSTRACT}

Body ecology is a micro-ecology. It is a discipline derived from philosophical naturism, deep ecology and holistic body-mind practices developed since 1850 in the corporeal experience of body recreation, outdoor living, and body awakening techniques using emersiology. It is because we transform the practices of individuals that ecology is transformed. This paper seeks to explain the new discipline of body ecology, and its focus on the significance of micro-situations and micro-experiences.

\section{KEYWORDS}

awareness; body ecology; cosmotic emersiology; philosophy of body

DOI

10.14712/23366052.2018.2

(c) 2018 The Authors. This is an open-access article distributed under the terms of the Creative Commons Attribution License (http://creativecommons.org/licenses/by/4.0), which permits unrestricted use, distribution, and reproduction in any medium, provided the original author and source are credited. 


\section{INTRODUCTION}

\section{Body ecology - a sustainable philosophy}

Body ecology (Andrieu et al., 2018) corresponds to the emersion of new sensible data during leisure. In ecologising, the body seems to undergo the effects of the environment in a passive way, whereas in the emersive leisures (Andrieu \& Loland, 2017), ecologisation is described by what is activated in emotions, affects and internal sensations such as empathy (Nobrega et al., 2017).

With pollution and climate change, the search for sustainable sports has become an ethical and aesthetic pursuit. Outdoor sports and sports in nature are now perceived as providing a genuine education for regulating the behaviours of leisure and adventure (Ewert \& Davidson, 2017). Outdoor adventure activities are becoming an increasingly popular part of physical education programmes. Practicing sustainable leisure is based on reconnecting with nature, as we see, for example, in surfing (Borne \& Ponting, 2017). The problem here is that the degree of commitment is more of a recreational kind than a prolonged contact with nature: the developers of outdoor adventure activities have to relate (and will have increasingly to relate) to a 'tainted' nature that does not always encourage healthy practices.

By immersing oneself in nature, practicing new forms of leisure and sport seems to prompt a feeling of belonging to the natural elements just as much as a feeling in the body of new emotions and sensations. Ecology is not just a discourse, but also a practice that engages our daily responsibility; it connects to body awareness through reflection on our actions and their consequences. Body ecology is a practice of selfcare that extends to a sense of responsibility for caring for others through our lifestyle choices. This is not about a return to an ideal state of nature, but an observation of our lifestyle and our ways of production and consumption. From this perspective on body ecology, the material elements, namely the air, water, sun and the earth itself, penetrate our bodies so that we also become ecological at the very moment in which we breathe, feel the warmth or the depth of the water, for example, in naturist or artistic practices.

If we do not know the ecology of our own bodies, we look to nature for a harmony that is actually within us: our microcosm no longer corresponds with the macrocosm. We look to the mountains, beaches or countryside landscapes and find a mismatch between the body and nature. To walk, take in the air, transform solar energy, sink into the earth, find pleasure in water, take the products of the earth and relish their taste: all are ways to green our bodies on a daily basis. If the body feels the effects of the elements without suffering them, then interactions with nature can no longer insulate us from the necessary ecological restoration of the environment.

The challenges of a cosmotic emersiology against the necessary ecological restoration of the environment consists in a more immersive practice of the body in its contact with nature: the body is thus modified by its prolonged immersion by finding the strength and the vital energy of the cosmos in a more holistic framework of the understanding of the interactions between its body and the natural elements. Thus ecologized sensations are awakened in the body, such as feeling alive and feeling the vitality of nature.

Body ecology is a micro-ecology. It is a discipline derived from philosophical naturism, deep ecology and holistic body-mind practices developed since 1850 in the cor- 
poreal experience of body recreation, outdoor living, and body awakening techniques. It is because we transform the practices of individuals that ecology is transformed. The idea is to create micro-micro-situations, such as the contemplation of a landscape, the observation of the elementary life of plants and insects and the experiencing of sensations of the elements - the wind, the air or the sun. Within body ecology, cosmotics is a cosmology that relates each natural element with the production of an internal effect in the body.

It must be said here that the new study of body ecology in sport and leisure studies is a description, embraced by philosophy, sociology, sports studies and ecology, of the living body's activity as a living body, and its effect on the perception of self, knowledge of the environment, and the ecologisation of the body. With body ecology, we describe how the implicit information processing below the threshold of consciousness determines the action modality, emotions and ecologisation of our body with nature, with others and with space.

\section{A new philosophy: an ecology of sport}

The ecology of sport (Andrieu \& Loland, 2017), along with body ecology and emersive leisures, is a new way of using bodily techniques when immersed in nature, in the elements, and inside one's body through the power of awareness. Leisure becomes emersive when it involves the production of new emotions in the body - new emotions are induced by emersive leisures. If we have never had these experiences previously, they are the new effect of the activation of the living body by body ecology; emersion is the activation and emergence of what is living in the body. With environmental ecology, the ecological conscience finds a way of preserving and fitting into ecosystems by using restorative and recycling techniques: ecological immersers may penetrate the wild and see the signs of human degradation, but they do so by defining a philosophy of aesthetics and of aesthetical immersion in the elements. The criticism of technical civilization has as its counterpart a description of the benefits of immersion in the cosmos of wildlife.

Emersive leisures are corporeal experiences of interaction with the world, as well as with the emotions that emerge in the course of corporeal engagement (Pepper, 1996). Playful recreation, when it is carried into sporting activity, finds a source of well-being and satisfaction: the aim seems to put motor control intentionally in the service of the non-competitive objectives of leisure. Arne Naess (2008, p. 19), like Thoreau, opened the way by ecologising himself during regular stays in his high-altitude Tvergastein hut. He asked: 'How can we explain that we are a part of this place when we were not raised here and have not always lived here?' By allowing emotions and sensations to emerse in the very place of body ecology, the milieu fosters modes of self-realisation as leisure unfolds.

Playful leisure procures pleasure that ends once it has been achieved, whereas emersive leisure pursues the effects of knowledge and sensory afterglow. In our recent book (Andrieu et al., 2018), we show how emersion in leisure occurs as a cosmic experience of nature (first section of the book), as a sensibility to echoes of the world in oneself (second section), and as the awakening of the living body in activities that elicit acute attention and meditation (third section). In corporeal engagement, emersive leisures activate unsuspected resources in the living body. An awakening by cor- 
poreal practices is the immersion of consciousness in bodily experience whose effects are not controlled by the act of becoming conscious. In order for the awakening of the living being to emerse - that is, to emerge unbidden into consciousness - the living body has to be activated to produce capability resources, until then unsuspected and unknown to consciousness, through its dynamic and spontaneous ecologisation.

We present here the sensory, emotional and symbolic processes that reflect the vast field of research that has often been presented as a 'blind spot' in the history of the human and social sciences. Immersers testify by the feeling of their flesh and the impression and imprint of the elements in their everyday struggles, as in Sigmund Loland's (1996) sports ecosophy, inspired by Arne Naess. Unlike nudists and naturists, who master their bodies by purifying them through reinvigoration, immersers plunge into nature to allow their bodies to feel modifications uncontrolled by the will, through sensory ecology. Examples might be the advance of the ice that forced Ernest Shackleton's (1874-1922) hibernation or Alexandra David-Néel's encounters with other cultures in far-away Tibet (1868-1969). When the will is not present, virtues allow a person to develop 'new' feelings in embodiment, respect for nature and acceptance of the man's belonging, as part of the cosmos.

Body ecology (Andrieu, 2008-2011; Andrieu \& Loland, 2017) is also based on philosophies of awakening and consciousness. These immersers into consciousness favour transcendental meditation and reflexivity in action through physical practices of consciousness. Although we might distinguish these techniques, the holistic context of each can cause confusion because the action on one part of the body would immediately be related to that of other parts. Only the subject in his or her physical, real-life experience can establish this correspondence, making efficient perceptions of health unverifiable but not improbable, although we do know that yogic meditation is able to modify the levels of cognitive activity. In causing a shift from a postural hyper-consciousness to a liberating consciousness, these emersive techniques are based on different levels of awareness.

The connections between body ecology and emersive leisure are the effects of ecologisation: immersed in the body, the living body activates unprecedented capability resources and thus encourages an involuntary emersion, going so far as to the awareness of new emotions. This activation is a new mode of self-knowledge in the very experience of body immersion. By awakening previously unknown internal sensations, we can observe thrills, osmosis with the elements, and the pain of injury - leisure allows the activity of the living body to emerse all the way toward the level of conscousness. Our great surprise at the vitality of our bodies suggests that this kind of leisure is less a sense of relaxation and more a sense of discovery and enhanced knowledge of ourselves and the world.

Olivier Sirost (2016), an ecological sociologist, has described this relation as separately gardened natures, culturalised natures, identified natures and the depletion of nature. The ecological sociology of sport reflects socio-historical progress: the possible release of an environmental nature by humans and, at same time, a refusal of the wilderness despite the desire for immersion. The search for emotion reflected in the new leisure falls short of the true nature that we still yearn for in interpreting the myth of Eden. The new body ecology, defined by Bernard Andrieu (2016), is a way of living in the corporeal world and the cosmos. This cosmic leisure must be understood as 
arising from the myths of an Edenic nature (rural and wilderness landscapes) and the utopias of returning to nature (body experiences, Monte Verità, youth movements, adventure novels, explorers' clubs, etc.).

\section{The influence of the emotional geography of sport}

The geography of sport and recreation was first described in 1962 by Terence M. Burley Hunter (1962, pp. 46-55). At the Valley Research Foundation in Australia, he had studied a means of locating body practices before they became a reflection upon the effects of territory and land on the practitioners' corporeal experience. He defined five aspects of the geolocalisation of sport: economic impact, social models, effects on society, cultural origins of practitioners and geographical distribution.

In 1969, John Rooney (Rooney \& Pillsbury, 1992) advanced the idea of sports regions with the publication of an atlas of American sports. Under the influence of Edward Relph, who introduced the term 'placelessness' in 1976, Karl Raitz (1995, IX) demonstrated how the interaction between the sports landscape and the game itself contributes to the bodily experience. This mapping approach to sports practice is not only quantitative and tourist-oriented for an economic market, but we can also understand it as emotional maps, like Yi-Fu Tuan's use of the term topophilia (Tuan, 1974). Tuan founded the study of environmental perception, attitudes, and values according to a humanistic model of geography, stressing the emotional connection between a place and a leisure practice.

Socio-spatial studies of territorial changes in the type of sports practices and their spatial patterns of distribution reveal how much embodied places and local spaces are changing the bodily experience of practitioners, as Bernard Jeu described (1977). However, using land for the purpose of personal entertainment does not follow the logic of sensory immersion in nature (Augustin, 1999). The feeling of space is built through contact with the earth and its elements on a given territory.

The emotional geography of sport has produced new questions: How are sports facilities built at the regional level? What is the spatial behaviour of the various practitioners? How can the geographical expression of a sport be characterised across a district? Territorial analysis of embodied sports practices is a way to analyse the influence of practitioners' life story curricula on their choices.

\section{An ecology of perception in the first person}

In the New History project of Marc Bloch and Lucien Febvre, one also finds the idea of body ecology. Invited by the Henri Berr International Centre for Synthesis, Lucien Febvre prepared Earth and Human Evolution, which clearly showed the influence of geography in the analysis of Humboldt's 'habitable earth' and Ratzel's ecumene. The difficulty of the undertaking lies in the limits of human geography, which remains deeply physical at its core, and those of social morphology and its Durkheimian coldness. If geography remains the science of places and not of people, if sociology remains the cold study of social facts, it is nevertheless true that 'people are geographical agents' (Febvre, 1970, p. 75).

For Marc Bloch, this last remark makes the historian a researcher of traces, residues deposited by experience, footprints left behind: "What do we mean by a document, if not a trace - that is, the mark - perceptible to the senses, that has left a phenomenon 
that is in itself impossible to grasp?" (Bloch, 1997, p. 71). Although Bloch distances himself from the body to a certain extent, as it is not the trace, the residue, or the imprint, Lucien Febvre has sought to develop a geography of the body, asking about what people once experienced through their senses, emotions and imaginations. In short, the historian's project is to examine the body through time and to specify the various different perceptions of the body. The recent work of Alain Corbin has mostly followed this perspective.

The rooting of symbolism in a matrix, a mother earth, is a reference to the philosophy of nature developed by Hölderlin. His poem provided the inspiration for the circle of the Munich Kosmiker - which included the poet Stefan George and the philosopher Ludwig Klages - that proposed an ecology of the body, reminding us that the body is part of the matrix of the earth from which symbols arise and from which it draws its power. This cosmic circle became closely connected with the pioneers of Monte Verità in Ticino, experimenting with vegetarianism, naturism and free movement in nature. The work on the poetics of habitation developed by Bachelard and his students has continued the analysis of myths and symbolism via the Eranos circle built on the traces of Monte Verità. There have been exciting developments in the geopoetics of Kenneth White and the travel literature of Michel Le Bris.

These different themes still provoke considerable international debate on body ecology. For example, for the psychologists of the movement, one might cite the controversy between James J. Gibson and E. Panofsky. In the Kantian tradition, Panofsky developed the idea of the Kunstwollen, where an artwork presents itself to us with a particular form and meaning that guides our judgement. Gibson dismissed this differentiation between vision and representation and defended the idea of an ecology of perception, with perception being an affordance or a pole of interactions accessible to exploration. Through the ecology of perception, the body mobilises and reveals itself as much as the environment that surrounds it.

It is this intuition that Augustin Berque addressed in an original way with the concept of mediancy, in which he shows that humans and their environments (natural and social) reveal themselves reciprocally, creating 'holds' that give the other the possibility of grabbing hold. In this way, he founded the relational logic of ecology: 'Phenomenological matrices (the schemes of perception and interpretation of the environment) thus cease to generate physical impressions (modes of environmental management), which in turn influence these matrices, and so on' (Berque, 2000, p. 44).

A recent disagreement concerns David Howes, a pioneer in sensory studies, and Tim Ingold, who developed an anthropology of habitation. According to Howes, the language of the senses is revealed in different ways, depending on the epoch and culture. Thus, there are ways to feel by mobilising the body differently, as proposed by art, medicine, legislation, politics or marketing (Howes \& Classen, 2014). On the contrary, Tim Ingold proposes a more transversal anthropology of the textual relations that people maintain with their beliefs or with nature. Ingold, like Gibson, emphasises affordances that he particularly analyses in an ecology of existence, habitation and skill.

\section{Wellbeing through Cosmotics}

Another route is possible (D’Andrea \& Sirost, 2017). As proposed by Michel Maffesoli, this is ecosophy, where one returns to animal passions, where the figure of Atlas does 
not merely bear the burdens of the world, but is also the Kosmokrator (sovereign of the Cosmos) (Maffesoli, 2017, p. 124). Beyond discourse that is plausible and rationalising, he has discovered a tone to the lived experience of space that is rather awkward to integrate into the modern worldview: the immediate sensation of incommensurability that makes humans feel minuscule and inert, lost in the immensity of nature. At the imaginal level, this primordial emotion prevents us from taking seriously the possibility of the direct interference of human actions on global equilibrium, which is in any case rejected because it is too close to an awareness of the essential frailty of our species.

In Austria, Germany and Switzerland, communities of Kosmikers (Sirost, 2016b) were founded. These poets, painters, architects, dancers, writers and academics from European Bohemia plunged into naturism, vegetarianism, nature cures, new forms of dance, new pedagogies, new music, Jugendstil, depth psychology, Eastern meditation, Bauhaus architecture, nature hikes and urban rambling. In Paris, Munich, London, New York, Vienna, and Darmstadt, artist communities and colonies flourished. One might audaciously cite Barbizon, Chicago, Monte Sol, and Esalen, as well. Just as scientific ecology explores plant communities, it is clear that similar explorations have driven the communities of bodies that have settled in a number of geographically limited places and radiated through European culture. Geographers were among them, like Elisee Reclus in connection with anarchist networks and Alpine clubs (Ferretti, 2014).

To become one with nature, the hermit/anchorite seeks refuge in a cave, Thoreau (1854) retired to his wooden hut in Walden, and John Muir (1954) found peace in a canyon of the Sierras, as did Sylvain Tesson (2014) in Siberia. Enclosure in nature intensifies the immersive effect. In the late 1970s, Thomas Rain Crowe returned to the Appalachians and lived for several years as a hermit. As he said about this experience of living deep in nature, in the wilderness: only the present moment exists. In the universe of desert-style nomadism, the criss-crossing of an entire continent, for full-time voyagers, is like the domestication of a wild territory. Kenneth White, in his cosmopoetic laboratory, found the ecospiritual description in Rimbaud, Gauguin and Victor Segalen as a temptation to surpass the West in an orientalism that is nevertheless still colonial.

Leaving behind the colonisation of nature and living beings, retreating into the woods - before it was the lot of the homeless, living and dying of cold and exhaustion in the open air - might have appeared as an attitude of physical, social and mental aeration. Solitude in nature can thus be understood as an immersion in living and vivifying air. Nonconformist Christians and utopian socialists shared this anti-modernist stance and embraced the romanticism of John Ruskin and William Morris: as early as 1820, hikers organised to discover nature (Harvey, 1997, p. 55).

Yet the wilderness may not exist and might never have existed because the pioneers never crossed virgin nature: it was always inhabited by natives. Although the earth has not always been for humanity, we should not consider it as an object or as a subject but as a transject - a journey of subjectivity in nature. The path of our planet finds in the ecologisation of our living bodies an infinite dynamics that surpasses us. Immersed in the earth, good cosmicists that we are, we cannot deconstruct the earth to make it our property. As mobile tenants, earthlings are never entirely earthly. In a modern acosmic world, Michel Collot's body cosmos defines itself, finds itself and deepens itself 
in nature: "Far from enclosing me within myself, this living and vibrant microcosm reveals that I belong to the macrocosm; I find, at the heart of my intimate coenaesthesia, the memory and the source of the emotions that lead me to an encounter with others and the universe" (Collot, 2008, p. 9).

\section{Immersive experience}

For Barry Lopez (1986), this earth, which we conceive through geography, pursues an existence perfectly independent in the artic nature: nature is not a landscape organised for our gaze, but a power that can overwhelm, as we know from stories of crossing the Arctic. The oceanic feeling, dear to Chateaubriand (2014), is found in Theodore Monod's desert crossing as an experiment of freedom in confinement (2017). This long period of cosmic immersion is that of the fluxes of the living in its processes of creation and the possibility of the death would be a permanent risk. The temptation is great to merge with nature, its spirits, its elements and its living beings. The cultures that are so empathic with nature express an 'imsertive' lifestyle by immersion-imsertion in the animal, in the force of the elements like an aboriginal dream: leaving one's own body to become the body of an animal or giving up the ego of one's own body in order to experience an 'other' body.

Imserted, cosmicists must ecologise their living bodies, otherwise they will undergo the otherness of nature as a fatal alteration of the fundamental rhythms. By transforming oneself from within, the cosmicists become part of the cosmos without reducing it or reducing themselves whenever they maintain a homeostasis between the inner environment and the external environment. An imbalance between the two produces dismosis with nature, others or technique. In nature rather than from nature, we would all like to awaken our deepest nature in an ideal unity and harmony between the inner cosmos and the infinite universe. This illusion, which may be mystical, naturist and anarchistic, also reveals an intuition and a sensitivity to nature. The desire to become one with wolves by living with them, as Shaun Ellis (2009) did, is not simply revisiting The Jungle Book or Greystoke: The Legend of Tarzan, Lord of the Apes. The universe cosmotises us by revealing its grandeur relative to our presence and actions, whereas our inner world is intensified by the echoes of the elements, of others and of the techniques within us. This intensification is the geography of the instant: the presence of the body is a direct incorporation of the qualities of the element.

The survivors of extreme environments are sometimes hailed as heroes, with their narratives reconstructed in fictional documentaries that render both the real and the false aspects of immersion in an illusory way: the camera is always at hand to serve the adventurer who wants to scare himself. Survival guides in hostile environments are proliferating in the name of survivalism: the need to have both physical techniques and adapted equipment so as to avoid dismosis and succeed at the trials of nature as proof, if not of one's virility, of one's flexibility. Extreme solo walks, like that of Sarah Marquis (2016), are a way to exalt nature as a whole: 'you have to be aware of the environment at all times' by discovering the limits of one's own body in full nature.

The experience of openness to space is thus tragic, which explains why current rhetoric is moving away from it, denying any correlation between vital activities and the places where they take place. In this way, humans are losing their place in the 
world, which is not only an environmental problem but also a crucial issue for the understanding and meaning of all existence. Humans renounce consciousness of the finitude revealed by their own corporeality, but at the same time they lose the possibility of belonging, of being part of something that this consciousness could give them. Only a new ecological thinking can balance the destabilising effect of knowing the boundaries inscribed in the flesh: another way of thinking, committed to surmounting the Cartesian separation between body and mind and recovering the richness of experience from an active relationship with matter and space, whether it be one's own body or the lost skill of inhabiting a place.

\section{Emersive recreation}

Emersive recreation does not encompass only those physical practices that are carried out at the heart of the geographical and institutional spaces of modern sport. Faced with urbanisation and polluted cities, Le Corbusier founded his playful revolution on the emergence of emersive leisure, starting from his own bodily experiences and from the idea of sports carried out in proximity to buildings. Emersive leisure must offer the possibility of a playful attitude to urban spaces, and in the 1930s this attitude found little favour. Le Corbusier's criticism of the architecture of industrial cities, particularly as he travelled through Brazil, Germany, and the United States, was based on the remoteness from natural conditions and the individual's distant relations to nature. With sports played close to buildings, leisure should be directly available from the ground floor to the roof terrace, where hydrotherapy, heliotherapy, and naturism are guaranteed and free.

Living in the air high up in the trees is not just a protection against predators, ${ }^{1}$ but an arboricultural lifestyle, like that of the Korowai people in Indonesia, whose homes are sometimes perched 35 metres above the understorey of the Irian Jaya rainforest. Between the sky and the earth, the canopy has become a place for exploring flora and fauna: Francis Hallé, Professor of Tropical Botany; Dany Cleyet Marrel, inventor, designer and aerostat pilot; and Gilles Ebersolt, inventor-architect of the Radeau des Cimes, ${ }^{2}$ lived in the canopy from 1986 to 2003 . This access to the treetops, at an altitude of about 50 metres, was accomplished with an airship that could land on the canopy and an inflatable raft (the Radeau des Cimes) functioning as a laboratory.

The ecological homes of green architecture offer the possibility of immersing oneself in nature while inhabiting one's body, as with Le Corbusier's shed in Cap Saint Martin, through the facilitation of interactivity with the sun and air. Inspired by the post-' 68 Rousseau-ist dream, the wooden house, no longer standing alone in the meadow, defines an interactive architecture. In France, until the 18th century, wood was omnipresent in popular construction. After World War II, economic constraints, the urgent need to rebuild, and the fashion of 'all concrete' - considered the most modern of materials - left wood as a building material far behind in second place.

With the Instituto Terra, Sebastião Salgado and his family began to combat deforestation and its accompanying run-off, which makes land infertile, and they did so by replanting spaces in the native forest of Minas Gerais. The ecosophy of Félix Guattari

www.opentreeclimbing.org

www.radeau-des-cimes.org 
finds here its three registers: "the environment, social relations and human subjectivity" (Guattari, 2018, p. 14). If the Earth is a living being, which is the Gaia hypothesis of James Lovelock (2000), it would be appropriate for Guattari to extend the ecosophy to other living, human, social and cultural systems.

Now the body is experienced as a conscious perception of the activity of the living body. Indeed, the living body is the biological activity of an organism through its body schema and aesthesiological systems, and it adapts informed consciousness. The living body became a central focus of philosophy when Lamarck examined the internal link between the biological transformations of the living body, forging the study of zoological philosophy. More than just a body, the living body is a philosophy of ecological and zoological import because of the interactions of its matter with the internal body through its porosity and its elasticity (Steigmann, 2017). Without this permeability, adaptation would not foster the greening dynamic that changes internal qualities towards a neuronal plasticity (Seil, 2000).

Access to the living body is difficult because one's activity is under the level of consciousness. Emersiology (Andrieu, 2018) is a method for perceiving movement: it is a re-knowing of the emotional information in the consciousness of the lived body even if this information was activated by the living body during its ecologisation. To make a reconnection with our living body, we can recosmise though body ecology to produce emersive leisures: this fully awakening implies a deepening of living through non-representationalist techniqus for emergence. The immersive scheme that can be deliberately organised produces involuntary emersive effects outside of the subject's control. Emersion is here an awakening of consciousness by involuntary movements, reflexive thrusts and direct feelings

The passage from phenomenology to cosmotic emersiology is a new step in describing the internal activation of the living body. The methodological difficulty and yet the interest of this research arises in great part from the need for a language of the living body: the emersion of internal sensation without conscious control is produced involuntarily through interactions with our environment and contact with other people. It might be better to rein the mind in, so that we can wholeheartedly welcome the activation of our brain and the ecologisation of the living body.

Emersense, the emersion of new meanings, awakens the living body in order to activate the production of novel unconscious meanings for the subject. Awakening the body means making it conscious through its own understanding. For although body emersions are unconscious, they are not inactive, because activation implements scenarios of decisions and emotions in the living body before even a single action is consciously realised. The living body incarnates meaning before it can express it in a linguistic structure likely to be recognized by a community during proxemic interaction. The difference between bodily intention and bodily consciousness of intention is useful for understanding the unconscious anticipation of the living body in relation to the voluntary action of the body. Between the two, affects, emotions and associative memory all nurture and stimulate the semantic production of the body, yet without consciousness always being able to reach it. The living narrative of emersive leisure begins before the ego knows it as such through the narrative form. 


\section{REFERENCES}

Andrieu, B. (2008-2011). L'écologie corporelle (4 tomes). Biarritz: Atlantica.

Andrieu, B. (2017). L'écologie corporelle (2 tomes). Paris: L'Harmattan.

Andrieu, B. (2018). Learning through my living body. Emersiology's method. Rouen: Presses Universitaires Rouen/CNAC.

Andrieu, B., \& Loland, S. (2017). The ecology of sport, with body ecology and emersive leisures. Leisure \& Society, 40(1), 1-4.

Andrieu, B., Parry, J., Porrovecchio, A., \& Sirost, O. (Eds.) (2018). Body Ecology \& Emersive Leisure. London: Routledge.

Augustin, J. P. (1999). Sport, Géographie et aménagement. Paris: Nathan.

Berque, A. (2000). Médiance de milieux en paysages. Paris: Belin.

Bloch, M. (1997). Apologie pour l'histoire ou Métier d'historien. Paris: Armand Colin.

Borne, G., \& Ponting, J. (2017). Sustainable Surfing. London: Routledge.

Burley, T. M. (1962). A note on the geography of sport. The Professional Geographer, 14, 55-56.

Chateaubriand, F. R. (2014). Memoirs from Beyond the Tomb. London: Peguin.

Collot, M. (2008). Le corps cosmos. Paris: Ed. La lettre volée.

D’Andrea, F., \& Sirost, O. (Eds.) (2017). Ecologies corporelles. Corps, n. 15. Paris: Ed. CNRS.

Ellis, S., \& Junor, P. (2009). The man who lives with wolves. New York: Three River Press.

Ewert, A., \& Davidson, C. (2017). Behavior and Group Management in Outdoor Adventure Education. Theory, research and practice. London: Routledge.

Febvre, L. (1970). La terre et l'évolution humaine. Paris: Albin Michel.

Ferretti, F. (2014). Elisée Reclus. Pour une géographie nouvelle. Paris: CTHS.

Guattari, F. (2018). Ecosophy. London: Bloomsbury Academic.

Harvey, T. (1997). A Claim on the Countryside. A History of the British Outdoor Movement.

Newcastle: Keele University Press.

Howes, D., \& Classen, C. (2014). Ways of sensing. Understanding the senses in society. London: Routledge.

Jeu, B. (1977). Le sport, l'émotion, l'espace. Paris: Vigot.

Loland, S. (1996). Outline of an ecosophy of sport. Journal of the Philosophy of Sport, 23(1), $70-90$.

Lopez, B. (1986). Artic Dreams. Imagination and Desire in a Northern Landscape. London: Macmillan.

Lovelock, J. (2000). Gaia: A New Look at Life on Earth. Oxford: Oxford University Press

Maffesoli, M. (2017). Ecosophie. Une écologie pour notre temps. Paris: Cerf.

Marquis, S. (2016). Wild by Nature. Main: Allen \& Unwin.

Monod T. (2017). Méharées et autres textes. Paris: Acte Sud.

Muir, J. (1954). The wilderness world of John Muir. Ed. Edwin Way Teale. Boston, NY: Mariner Books.

Naess, A. (2008). Un exemple de lieu: Tvergastein, in The Ecology of Wisdom. Berkeley: Counterpoint (trad. Fr. Pierre Dadelin. La réalisation de soi (pp. 9-35). Marseille: Wildproject).

Nobrega, P., Shirrer, M., Legendre, A., \& Andrieu, B. (2017). Sensing the living body: three degree of conscious awareness (pp. 40-57). Staps, 117-118.

Pepper, D. (1996). Modern environmentalism. An introduction. London: Routledge.

Raitz, K. (1995). The Theater of Sport. Baltimore: The John Hopkins University Press.

Relph, E. (1976). Place and Placelessness. London: Pion.

Rooney, J., Pillsbury, R. (1992). Atlas of American Sport. New York: Macmillan.

Seil, F. J. (2000). Neural plasticity and regeneration. London: Elsevier Science.

Shusterman, R. (2007). Body Consciouness. Cambridge: Cambridge University Press.

Sirost, O. (2016a). Foundations of French sensorial anthropology. Senses \& Society, 11(3), pp. 333-344. London: Routledge. 
Sirost, O. (2016b). Les kosmikers, Sociétés. N. Ecologie corporelle (pp. 56-64). Bruxelles: De Boeck.

Steigmann, D. (2017). Finite elasticity theory. Oxford: Oxford University Press.

Tesson, S. (2014). Consolations of the Forest: Alone in a Cabin in the Middle Taiga. London: Penguin.

Thoreau, D. (1854). Walden. London: Penguin Classics.

Tuan, Y. F. (1974). Topophilia, A study of environmental perception, attitudes, and values. Englewood Cliffs: NJ Prentice-Hall. 